\title{
Desidratação por imersão-impregnação e secagem por convecção de goiaba
}

\author{
Valéria Aparecida Vieira Queiroz ${ }^{(1)}$, Pedro Amorim Berbert(2), Marília Amorim Berbert de Molina(2), \\ Geraldo de Amaral Gravina ${ }^{(2)}$, Luciano Rodrigues Queiroz $^{(2)}$ e Rosires Deliza ${ }^{(3)}$
}

\begin{abstract}
(1)Embrapa Milho e Sorgo, Caixa Postal 151, CEP 35701-970 Sete Lagoas, MG. E-mail: valeria@cnpms.embrapa.br (2)Universidade Estadual do Norte Fluminense Darcy Ribeiro, Av. Alberto Lamego, no 2.000, CEP 28013-602 Campos dos Goytacazes, RJ. E-mail: pberbert@uenf.br, mberbert@uenf.br, gravina@uenf.br, Iqueiroz@uenf.br(3)Embrapa Agroindústria de Alimentos, Av. das Américas, no 29.501, CEP 23020-470 Rio de Janeiro, RJ. E-mail: rodeliza@ctaa.embrapa.br
\end{abstract}

Resumo - O objetivo deste trabalho foi avaliar as características físico-químicas e sensoriais de goiabas in natura e submetidas à desidratação por imersão-impregnação e à secagem complementar por convecção, além de avaliar a estabilidade da cor das goiabas secadas após 30, 60 e 90 dias de armazenamento sob refrigeração. Amostras de goiaba foram imersas em soluções de sacarose a $0,4 \mathrm{e} 0,5 \mathrm{~g} \mathrm{~mL}^{-1}$, sacarose a $0,3 \mathrm{~g} \mathrm{~mL}^{-1}+$ sucralose a $0,2 \mathrm{~g} \mathrm{~L}^{-1}$, açúcar invertido a $41 \%$ (p/p) e açúcar invertido sem diluição. Foram avaliados sólidos solúveis totais, acidez titulável, $\mathrm{pH}$, cor, aroma, aparência, sabor e textura. O teor de sólidos solúveis totais das amostras aumentou linearmente em função do tempo de imersão, sem efeito significativo do tipo de açúcar empregado no preparo da solução. A preservação do teor de ácido cítrico foi mais pronunciada em soluções menos concentradas de sacarose. Amostras secadas não submetidas à desidratação osmótica exibiram maior alteração de cor do que aquelas previamente desidratadas. Soluções de sacarose são mais eficazes na estabilidade da cor do que as de açúcar invertido. As goiabas submetidas à desidratação por imersão-impregnação tiveram boa aceitação sensorial, e aquelas secadas apenas por convecção não foram aceitas pelos provadores.

Termos para indexação: Psidium guajava, desidratação osmótica, açúcar, qualidade, conservação de alimentos.

\section{Osmotic dehydration and convective drying of guava}

\begin{abstract}
The objective of this work was to assess physicochemical and sensory properties of fresh and osmotically dehydrated guava submitted to convective air drying. Color stability of the dried fruits was also analyzed after 30,60 and 90 days of storage under refrigeration. Guava slices were immersed into solutions of sucrose at 0.4 and $0.5 \mathrm{~g} \mathrm{~mL}^{-1}$, of sucrose $0.3 \mathrm{~g} \mathrm{~mL}^{-1}+$ sucralose at $0.2 \mathrm{~g} \mathrm{~L}^{-1}$, of inverted sugar at $41 \%(\mathrm{w} / \mathrm{w})$ and undiluted inverted sugar syrup. Total soluble solids, total titratable acidity, $\mathrm{pH}$, color, aroma, appearance, flavor and texture were evaluated. Soluble solids increased linearly in function of immersion time with no effect of the type of solute employed. Less concentrated sucrose solutions showed higher citric acid preservation in guava slices. Dried samples that were not submitted to osmotic dehydration showed higher color alteration when compared to those osmotically dehydrated. Sucrose solutions were more effective in maintaining color stability than inverted sugar syrups. Osmotically dehydrated guavas were well accepted by consumers, while convectivedried guavas were rejected.
\end{abstract}

Index terms: Psidium guajava, osmotic dehydration, sugar, quality, food conservation.

\section{Introdução}

Entre as frutas produzidas em regiões tropicais e subtropicais, a goiaba (Psidium guajava L.) se destaca não só pelo seu aroma e sabor agradáveis, como também pela sua rica composição nutricional, que apresenta teores elevados de vitamina $\mathrm{C}$, minerais, fibras, beta-caroteno e licopeno. Trata-se de fruto que exibe intenso metabolismo pós-colheita, o que o torna altamente perecível, com capacidade de conservação de apenas três dias, quando mantido em ambiente a $25-30^{\circ} \mathrm{C}$. Portanto, faz-se necessária a busca de alternativas de processamento que permitam prolongar o período de consumo do fruto e que contribuam para o aproveitamento do excedente da produção (Wilberg \& Rodriguez-Amaya, 1995; Gorinstein et al., 1999; Ali \& Lazan, 2001; Queiroz et al., 2006). 
A secagem é uma das técnicas tradicionais de conservação de alimentos mais utilizadas. Consiste na redução da disponibilidade de água para o desenvolvimento de microrganismos e para reações bioquímicas deteriorativas. Apresenta a vantagem de ser simples e permitir a obtenção de produtos com maior vida de prateleira. Além disso o processo envolve custos e volumes menores de acondicionamento, armazenagem e transporte. Em alguns casos, a desidratação apresenta a vantagem adicional de colocar ao alcance do consumidor uma maior variedade de produtos alimentícios que podem ser disponibilizados fora da safra, como é o caso das frutas secas (Park et al., 2002).

Apesar dos aspectos positivos, a secagem pode alterar as características sensoriais e o valor nutricional dos alimentos, e a intensidade dessas alterações é dependente das condições utilizadas no processo de secagem e das características próprias de cada produto. As frutas desidratadas devem preservar o sabor, o aroma e a cor originais, e devem, preferencialmente, estar livres de aditivos químicos e apresentar textura semelhante ao do produto fresco.

A desidratação por imersão-impregnação (DII), também denominada desidratação osmótica, tem sido utilizada como pré-tratamento que melhora algumas propriedades nutricionais, sensoriais e funcionais do produto seco (Torreggiani \& Bertolo, 2001). A retirada parcial de água é obtida por imersão da matéria-prima em soluções hipertônicas onde a complexa estrutura da parede celular dos alimentos age como uma membrana semipermeável, não completamente seletiva aos íons e compostos presentes tanto na solução osmótica quanto no interior do alimento (Lenart \& Piotrowski, 2001). Estabelece-se assim um fenômeno caracterizado por três tipos de fluxo: água do produto para a solução; soluto da solução para o produto; e solutos naturais do produto, como ácidos orgânicos, minerais e vitaminas, para a solução (Raoult-Wack et al., 1994), com conseqüente alteração de sua composição química.

Parâmetros como a cor, sabor e aroma de frutas, sensíveis à secagem por convecção em ar aquecido, foram melhorados quando uma etapa prévia de desidratação por imersão-impregnação foi utilizada (Lazarides et al., 1997; Ikoko \& Kuri, 2007). O uso de temperaturas moderadas de operação, bem como o fato de a água ser removida do alimento, sem que haja nenhuma mudança de fase, contribui também para a melhoria da qualidade do produto final. $\mathrm{O}$ sabor de uma fruta desidratada por imersão-impregnação, em soluções de açúcares, é mais suave e mais doce que o da fruta in natura, em razão da absorção de açúcar e da difusão de parte das substâncias de baixo peso molecular da fruta para a solução osmótica, juntamente com água (Lenart, 1996). Além disso, a desidratação por imersãoimpregnação melhora a textura e a estabilidade dos pigmentos durante a secagem e o armazenamento de frutas (Krokida et al., 2000; Riva et al., 2005).

Os efeitos da combinação dos processos de desidratação por imersão-impregnação e da secagem por convecção sobre a qualidade da goiaba são ainda pouco conhecidos. Sousa et al. (2003) avaliaram parâmetros físico-químicos e sensoriais de goiabas desidratadas osmoticamente, seguidas de secagem em estufa, tendo empregado apenas solução de sacarose a $65^{\circ}$ Brix. Panadés et al. (2006) estudaram os efeitos da temperatura, pressão, tempo de imersão e concentração de soluções de sacarose sobre a cinética da desidratação por imersão-impregnação (redução de massa, perda de água e ganho de sólidos).

O objetivo deste trabalho foi avaliar as características físico-químicas e sensoriais de goiabas in natura, submetidas à desidratação por imersão-impregnação e secagem complementar por convecção, além de avaliar a estabilidade da cor dessas goiabas depois de 30, 60 e 90 dias de armazenamento sob refrigeração.

\section{Material e Métodos}

Foram utilizadas 126 goiabas (Psidium guajava) da cultivar Pedro Sato, safra 2004/2005, provenientes de pomares comerciais do Município de Cachoeiras de Macacu, RJ, em estádio de maturação 2, caracterizado pela coloração verde clara da casca, com ângulo de cor $\left({ }^{\circ} \mathrm{h}\right)$ entre 113 e 116 , e que apresentavam uniformidade de tamanho e ausência de dano. Os frutos selecionados foram acondicionados em bandejas de plástico e armazenados sob refrigeração, em câmaras do tipo BOD, a $7^{\circ} \mathrm{C}$, até atingir o estádio de maturação 3 , caracterizado pela cor verde-amarelada da casca, com ângulo de cor entre 109 e 112.

Antes do início de cada teste experimental, 18 frutos foram retirados do ambiente de armazenamento, lavados em água corrente e imergidos em solução de detergente neutro a $1 \%$ por $15 \mathrm{~min}$. Posteriormente, foram enxaguados em água corrente, sanitizados em solução de hipoclorito de sódio a 100 ppm por 15 min e secados com papel toalha. Em seguida, os frutos foram 
descascados e cortados transversalmente, tendo-se retirado as sementes e dividido cada metade em outras quatro partes, de modo a se obterem oito frações por fruto, num total de 144 amostras. Retiraram-se, então, 18 frações, ou seja, uma amostra por fruto, para caracterização do fruto in natura, as quais foram imediatamente mergulhadas em nitrogênio líquido por $5 \mathrm{~s}$. Em seguida, essas amostras foram acondicionadas em frasco de polietileno branco fosco de $30 \mathrm{~mL}$ e armazenadas em freezer a $-18^{\circ} \mathrm{C}$, para análises físicoquímicas posteriores (sólidos solúveis totais, acidez total titulável, pH e cor).

Para evitar o escurecimento enzimático das amostras, as 126 frações restantes foram branqueadas em vapor d'água por $1 \mathrm{~min}$; foram, em seguida, colocadas em saco de plástico e imergidas em banho de gelo por 1 min. As amostras resfriadas foram imergidas em solução de ácido ascórbico $1 \%$ por 5 min. Depois das etapas de branqueamento e de imersão em solução de ácido ascórbico, retirou-se mais uma fração de 1/8 de cada fruto para as análises físico-químicas (sólidos solúveis totais, acidez total titulável, pH e cor). As 108 frações restantes, seis de cada goiaba, foram submetidas à desidratação por imersão-impregnação, nas seguintes soluções (tratamentos): sacarose a $0,5 \mathrm{~g} \mathrm{~mL}^{-1}$, sacarose a $0,4 \mathrm{~g} \mathrm{~mL}^{-1}$, sacarose a $0,3 \mathrm{~g} \mathrm{~mL}^{-1}$ e sucralose a $0,2 \mathrm{~g} \mathrm{~L}^{-1}$, açúcar invertido a $41 \%(\mathrm{p} / \mathrm{p})$ e xarope de açúcar invertido sem diluição, tendo-se empregado a relação fruta:xarope de 1:10 (p/p). Para as análises de cor e sensorial, foi utilizado, também, um tratamento controle, em que as amostras foram secadas por convecção diretamente em secador, sem desidratação por imersãoimpregnação prévia. A desidratação foi feita pela imersão das amostras na solução osmótica a $50^{\circ} \mathrm{C}$, em béqueres de vidro de $1.000 \mathrm{~mL}$, dispostos em três agitadoras-incubadoras de bancada (B. Braun Biotech, modelo Certomat U/Certomat HK) de movimento orbital, com freqüência de agitação de $60 \mathrm{~min}^{-1}$ e tempo de incubação de 2 horas. A sacarose foi adquirida no mercado local, e o xarope de açúcar invertido utilizado, Gludex 216 com taxa de inversão $\geq 90 \%$, foi fornecido pela Dulcini Alimentos. O edulcorante em pó sucralose (1,6-dicloro-1,6-dideoxi- $\beta$-D-frutofuranosil-4-cloro4-deoxi- $\alpha$-D-galactopiranosídeo) foi obtido na empresa Attivos Magisttrais. As soluções osmóticas foram preparadas com água destilada, autoclavadas a $120^{\circ} \mathrm{C}$ por $20 \mathrm{~min}$, e foram estocadas sob refrigeração a $7^{\circ} \mathrm{C}$, em BOD, até sua utilização.
Após a desidratação por imersão-impregnação, as amostras de goiaba foram enxaguadas com água destilada, para remoção do filme de açúcar formado na superfície e, em seguida, foram envolvidas em papel absorvente para retirada do excesso de água. Depois dessa etapa, foram retiradas outras 18 amostras de cada fruto, para análises físico-químicas posteriores (sólidos solúveis totais, acidez total titulável, $\mathrm{pH}$ e cor). As cinco frações restantes de cada fruto (90 amostras) foram, então, submetidas à secagem por convecção, em protótipo de secador do tipo gabinete, com bandejas. Utilizou-se apenas uma temperatura e velocidade do ar de secagem, $60^{\circ} \mathrm{C}$ e $1,25 \mathrm{~m} \mathrm{~s}^{-1}$, respectivamente. A secagem foi encerrada quando o teor de água do produto, determinado por gravimetria, atingiu valores entre 18 e $20 \%$ b.u.

O teor de sólidos solúveis totais (SST, ${ }^{\circ}$ Brix), nas amostras de goiaba in natura, após a imersão na solução de ácido ascórbico, durante a desidratação por imersãoimpregnação - nos tempos zero (considerado após a imersão em solução de ácido ascórbico), 0,08, 0,25, 0,5, $0,75,1,1,5$ e 2 horas - foi determinado com refratômetro portátil Atago, modelo HSR 500, de acordo com Association of Official Analytical Chemists (1990). O pH e a acidez total titulável (porcentagem de ácido cítrico), nas mesmas amostras in natura, após a imersão em solução de ácido ascórbico, a desidratação por imersãoimpregnação (nos diferentes tratamentos) e a secagem por convecção, foram determinados por meio de potenciômetro Digimed, modelo DM 20, e por titulação com $\mathrm{NaOH}$ 0,1 N (Association of Official Analytical Chemists, 1990), respectivamente. Os parâmetros relativos à cor $\left(\mathrm{L}^{*}, \mathrm{a}^{*}, \mathrm{~b}^{*} \mathrm{e}^{\circ} \mathrm{h}\right)$ foram determinados com colorímetro Minolta, modelo CR 300, em três pontos distintos das amostras de goiaba in natura, e nas mesmas amostras após a imersão em solução de ácido ascórbico, a desidratação por imersão-impregnação, a secagem por convecção, e após 30, 60 e 90 dias de armazenamento em BOD, a $7^{\circ} \mathrm{C}$.

A análise sensorial em relação ao aroma, aparência geral, textura e sabor foi feita por meio do teste de aceitação, tendo-se utilizado escala hedônica estruturada de nove pontos, em que: 1, desgostei extremamente; 2, desgostei muito; 3, desgostei moderadamente; 4, desgostei ligeiramente; 5 , não gostei, nem desgostei; 6 , gostei ligeiramente; 7 , gostei moderadamente; 8 , gostei muito; 9, gostei extremamente. Foram oferecidas a 77 provadores consumidores de goiaba, de forma monádica, quatro amostras de goiaba secadas, que foram 
desidratadas por imersão-impregnação, e uma amostra secada sem desidratação por imersão-impregnação. No teste de intenção de compra, depois de experimentarem as amostras, os provadores assinalaram no mesmo formulário se comprariam ou não o produto oferecido.

Nas análises estatísticas dos dados obtidos nas determinações físico-químicas, utilizou-se o delineamento experimental em blocos ao acaso, com arranjo fatorial (quatro ou cinco tratamentos de desidratação x quatro, sete ou nove períodos de amostragem), em que cada fruto correspondia a um bloco. Foi utilizado um tratamento adicional (controle, sem desidratação por imersão-impregnação), para a análise sensorial e para a avaliação da cor. Para as análises do teor de sólidos solúveis, foram utilizadas três repetições e, para as demais análises físico-químicas, utilizaram-se quatro repetições.

Os dados obtidos foram submetidos à análise de variância, após verificação da normalidade dos dados e homogeneidade das variâncias dos tratamentos pelos testes de Liliefors e Barttlet, respectivamente. As interações significativas pelo teste $F$ foram desdobradas, e as médias dos tratamentos foram comparadas pelo teste de Tukey, a 5\% de probabilidade, exceto o teor de sólidos solúveis, que foi analisado por meio de regressão.

$\mathrm{Na}$ análise sensorial, foi utilizado o delineamento experimental inteiramente casualizado, com cinco tratamentos e 77 repetições (participantes do teste de aceitação). Os dados obtidos foram submetidos à análise de variância e testados por meio do teste F. As médias foram comparadas pelo teste de Tukey, a 5\% de probabilidade. As análises estatísticas foram realizadas com o SAEG (Sistema para Análises Estatísticas e Genéticas), versão 9.0, em ambiente Windows (Ribeiro Júnior, 2001).

\section{Resultados e Discussão}

As amostras de goiaba in natura apresentaram teor médio de sólidos solúveis totais ( $\left.{ }^{\circ} \mathrm{Brix}\right)$ de 8,6 , que foi reduzido em média para 6,5, após a imersão em ácido ascórbico. Após a desidratação por imersãoimpregnação, nas diferentes soluções utilizadas, o teor de SST das amostras apresentou aumento linear significativo com o tempo de desidratação (Tabela 1). Esse efeito do teor de SST também foi observado por Valera et al. (2005), na desidratação osmótica de manga.
Na desidratação por imersão-impregnação houve redução significativa do teor de ácido cítrico, em quase todos os tratamentos, com exceção das amostras desidratadas em solução de sacarose + sucralose (Tabela 2). Observou-se, também, maior retenção de ácido cítrico, nas amostras tratadas em solução osmótica com menor concentração de açúcar. Em razão da solubilidade elevada do ácido cítrico em água, provavelmente, a solução de sacarose + sucralose provocou menor grau de lixiviação deste ácido graças à menor perda de água. Esses resultados estão de acordo com os apresentados por Maestrelli et al. (2001), que observaram redução da acidez titulável de 19,17 e 21,14 para 11,84 e 11,07 meq $100 \mathrm{~g}^{-1}$ (38,24 e 47,63\%), em esferas de melão desidratadas em solução de sacarose a $60 \%$, e para 12,63 e 11,86 meq $100 \mathrm{~g} \mathrm{~g}^{-1}(34,11$ e $48,41 \%)$ naquelas secadas apenas em secador com circulação de ar, para as cultivares Rony e Mirado, respectivamente. Peiró et al. (2006) também verificaram perdas de ácido cítrico entre 18 e $32 \%$ e entre 30 e $44 \%$, em operações sucessivas de desidratação osmótica de "grapefruit" (toranja) e abacaxi, respectivamente, em soluções de sacarose a $55^{\circ}$ Brix.

Apesar das variações de acidez titulável, não foram verificadas alterações significativas nos valores de $\mathrm{pH}$, ao longo do processamento, na maioria dos tratamentos, exceto no tratamento sacarose a $0,3 \mathrm{~g} \mathrm{~mL}^{-1}+$ sucralose a $0,2 \mathrm{~g} \mathrm{~L}^{-1}$, em que o $\mathrm{pH}$ foi significativamente maior na etapa de secagem por convecção (SC) do que na etapa de imersão em solução de ácido ascórbico (IAA) (Tabela 2). O pH expressa a concentração de íons $\mathrm{H}^{+}$livres por meio de função logarítmica, assim, o decréscimo ou acréscimo de uma unidade no valor de $\mathrm{pH}$, representaria um aumento ou redução de 10 vezes na concentração de $\mathrm{H}^{+}$. Portanto, o fato de as reduções nos valores de $\mathrm{pH}$ não terem sido estatisticamente significativas, na maioria das amostras, não significa que

Tabela 1. Equações e coeficientes de determinação $\left(\mathrm{R}^{2}\right)$ relativos ao teor estimado de sólidos solúveis totais $\left({ }^{\circ} \mathrm{Brix}\right) \mathrm{de}$ amostras de goiaba, em razão do tempo $(0,0,08,0,25,0,5,0,75$, $1,1,5$ e 2 horas) de desidratação osmótica, em diferentes soluções.

\begin{tabular}{lcc}
\hline Tratamento & Equação de regressão & $\mathrm{R}^{2}$ \\
\hline Sacarose a $0,5 \mathrm{~g} \mathrm{~mL}^{-1}$ & $\mathrm{y}=6,0332 * * \mathrm{x}+9,8940$ & 0,89 \\
Sacarose a $0,4 \mathrm{~g} \mathrm{~mL}^{-1}$ & $\mathrm{y}=4,3172 * * \mathrm{x}+9,1856$ & 0,85 \\
Sacarose a $0,3 \mathrm{~g} \mathrm{~mL}^{-1}+$ & $\mathrm{y}=2,9871 * * \mathrm{x}+7,5631$ & 0,85 \\
sucralose a $0,2 \mathrm{~g} \mathrm{~L}^{-1}$ & & \\
Açúcar invertido sem diluição & $\mathrm{y}=9,4011 * * \mathrm{x}+9,9052$ & 0,93 \\
\hline
\end{tabular}

**Significativo a $1 \%$ de probabilidade pelo teste $\mathrm{t}$. 
não possam ocorrer alterações na sua acidez durante o processamento. No entanto, a acidez titulável reflete o potencial de $\mathrm{H}^{+}$que está presente na solução e, por não ser representada por função logarítmica, apresentou maior variação de valores, o que foi confirmado pela ANOVA. Forni et al. (1997) também não observaram variações significativas no $\mathrm{pH}$, após a desidratação por imersão-impregnação de cubos de damasco em soluções de sacarose a $65 \%$.

A cor das amostras de goiaba se manteve estável em todos os tratamentos, e não se verificou diferença significativa nos parâmetros de cor avaliados do início (in natura) até o final do processo de desidratação por imersão-impregnação (Tabela 3). Além do efeito da desidratação, esse resultado pode ser atribuído, em parte, ao branqueamento e à imersão em ácido ascórbico das amostras, na fase inicial do experimento, o que evitou o escurecimento enzimático. Ao final da secagem por convecção, exceto no caso dos tratamentos com açúcar invertido, a maior parte das amostras continuou a exibir estabilidade da cor quanto ao parâmetro L* (Tabela 3). Esse resultado diverge dos obtidos por Sousa et al. (2003), que verificaram tendência ao escurecimento em goiabas da cultivar Paluma tanto após a desidratação osmótica, em sacarose a $65^{\circ}$ Brix, quanto após a secagem. Neste trabalho, os valores de L* apresentaram redução significativa apenas nas amostras tratadas com açúcar invertido. Esse fato pode ter ocorrido em razão da natureza do soluto impregnado na fruta, durante a desidratação por imersão-impregnação, que associado ao aumento da temperatura, durante a secagem, favoreceu os processos de escurecimento não enzimático, como as reações de Maillard, caramelização e oxidação do ácido ascórbico. Os substratos para essas reações são compostos carbonílicos, principalmente os açúcares redutores como a frutose e a glicose, que estão presentes em grande quantidade no açúcar invertido utilizado neste trabalho ( $>90 \%$ de inversão). A sacarose é uma molécula carente de função redutora livre e não afeta, portanto, o escurecimento não enzimático nas amostras desidratadas com este soluto. Krokida et al. (2000) também observaram maior estabilidade da luminosidade, durante a secagem de amostras de maçã e de banana, pré-tratadas osmoticamente, em relação àquelas não desidratadas previamente.

Enquanto os valores de L* mantiveram-se estáveis, ao final da secagem por convecção para a maioria dos tratamentos, com exceção dos tratamentos com açúcar invertido, os valores de $\mathrm{a}^{*}$ apresentaram aumento significativo em todos os tratamentos, com intensificação da cor vermelha ao final da secagem (Tabela 3). Quanto ao parâmetro $b^{*}$, o aumento ao final da secagem só foi verificado na desidratação em soluções com sacarose a 0,4 e $0,5 \mathrm{~g} \mathrm{~mL}^{-1}$. Isto se deve, possivelmente, ao efeito da concentração dos pigmentos com a desidratação drástica que ocorre nessa etapa. Forni et al. (1997) não observaram alterações significativas nos valores de $\mathrm{a}^{*}$ e b*, após a secagem de damascos pré-desidratados osmoticamente; esse fato foi atribuído à ação antiescurecimento enzimático do ácido ascórbico, aplicado antes da desidratação, o qual sofreu severa redução durante o processo de secagem. A vitamina $\mathrm{C}$ se oxida e reduz as o-quinonas, formadas pelas polifenoloxidases em dihidroxifenóis que possuem menor intensidade de cor.

Após 30 dias de armazenamento em BOD a $7^{\circ} \mathrm{C}$, apenas as amostras pré-tratadas com 0,5 e $0,4 \mathrm{~g} \mathrm{~mL}^{-1}$ de sacarose apresentaram redução significativa da

Tabela 2. Acidez total titulável (porcentagem de ácido cítrico, b.s.) e pH de goiabas in natura e ao final das diversas etapas de processamento, para as diferentes soluções osmóticas utilizadas ${ }^{(1)}$.

\begin{tabular}{|c|c|c|c|c|c|}
\hline Etapa $^{(2)}$ & $\begin{array}{c}\text { Sacarose } \\
0,5 \mathrm{~g} \mathrm{~mL}^{-1}\end{array}$ & $\begin{array}{c}\text { Sacarose } \\
0,4 \mathrm{~g} \mathrm{~mL}^{-1} \\
\end{array}$ & $\begin{array}{l}\text { Sacarose } 0,3 \mathrm{~g} \mathrm{~mL}^{-1} \\
+ \text { sucralose } 0,2 \mathrm{gL}^{-1}\end{array}$ & $\begin{array}{c}\text { Açúcar invertido } \\
41 \%(\mathrm{p} / \mathrm{p})\end{array}$ & $\begin{array}{c}\text { Açúcar invertido } \\
\text { sem diluição }\end{array}$ \\
\hline & & & Acidez total titulável & & \\
\hline IN & $2,89 a$ & $3,63 a$ & $3,13 \mathrm{a}$ & $3,14 \mathrm{a}$ & $3,60 \mathrm{a}$ \\
\hline IAA & $3,06 \mathrm{a}$ & $3,87 \mathrm{a}$ & $3,18 \mathrm{a}$ & $3,51 \mathrm{a}$ & $3,49 a$ \\
\hline DII & $1,50 \mathrm{~b}$ & $2,01 b$ & $2,49 \mathrm{ab}$ & $1,98 b$ & $1,63 b$ \\
\hline \multirow[t]{2}{*}{$\mathrm{SC}$} & $0,95 b$ & $1,30 \mathrm{~b}$ & $1,69 \mathrm{~b}$ & $1,84 \mathrm{~b}$ & $1,04 \mathrm{~b}$ \\
\hline & & & $\mathrm{pH}$ & & \\
\hline IN & $4,27 \mathrm{a}$ & $3,79 \mathrm{a}$ & $4,27 \mathrm{ab}$ & $4,04 \mathrm{a}$ & $3,95 \mathrm{a}$ \\
\hline IAA & $4,20 \mathrm{a}$ & $3,79 a$ & $4,13 b$ & $3,96 a$ & $3,78 \mathrm{a}$ \\
\hline DII & $4,13 \mathrm{a}$ & $3,73 \mathrm{a}$ & $4,32 \mathrm{ab}$ & $4,03 \mathrm{a}$ & $3,99 a$ \\
\hline $\mathrm{SC}$ & $4,06 \mathrm{a}$ & $3,97 \mathrm{a}$ & $4,40 \mathrm{a}$ & $4,03 \mathrm{a}$ & $3,95 \mathrm{a}$ \\
\hline
\end{tabular}

${ }^{(1)}$ Valores seguidos por letras iguais, na coluna, não diferem entre si pelo teste de Tukey, a 5\% de probabilidade. ${ }^{(2)}$ IN: in natura; IAA: imersão em solução de ácido ascórbico; DII: desidratação por imersão-impregnação; SC: secagem por convecção. 
luminosidade, tendo-se tornado mais escuras, porém mantendo os mesmos valores de $\mathrm{L}^{*}$ nos meses subseqüentes (Tabela 3). Em todos os tratamentos, os valores de $\mathrm{a}^{*}$ diminuíram significativamente, tendo-se tornado semelhantes aos da fruta in natura e, apenas no tratamento com sacarose a 0,4 e $0,5 \mathrm{~g} \mathrm{~mL}^{-1}$, houve redução nos valores de $\mathrm{b}^{*}$. Com exceção dos tratamentos com açúcar invertido, não houve redução progressiva significativa na intensidade da cor vermelha (parâmetro $\mathrm{a}^{*}$ ), ao longo do período de armazenamento. De acordo com Calligaris et al. (2002), a perda de cor em purê de tomate armazenado em freezer é acompanhado pela redução no teor de carotenóides que, assim como na goiaba, é representada, em sua maior parte, pelo licopeno, pigmento bastante propenso à oxidação.

As amostras secadas por convecção, sem desidratação por imersão-impregnação, apresentaram maior valor ${ }^{\circ} \mathrm{h}$ ao longo do período de armazenamento (Tabela 3). Isso evidencia que a cor vermelha diminuiu e a amarela se intensificou ao longo do armazenamento. As amostras previamente submetidas à desidratação, por imersão-impregnação com sacarose a $0,5 \mathrm{~g} \mathrm{~mL}^{-1}$, apresentaram maior retenção da cor, com valores de ${ }^{\circ} \mathrm{h}$ iguais. Houve melhor retenção da cor durante o período de armazenamento, em goiabas submetidas à desidratação por imersão-impregnação, em soluções com maior concentração de soluto.

$\mathrm{Na}$ avaliação sensorial, foram consideradas aceitas as amostras que receberam, em média, nota superior a 5 (não gostei, nem desgostei). As amostras não submetidas à desidratação por imersão-impregnação não foram aceitas pelos participantes, quanto aos atributos aparência, sabor e textura, com notas entre 2 (desgostei muito) e 4 (desgostei ligeiramente). Apenas em relação ao aroma, essas amostras foram consideradas aceitas

Tabela 3. Parâmetros de cor ( $\mathrm{L}^{*}, \mathrm{a}^{*}$ e b*) e ângulo de cor $\left({ }^{\circ} \mathrm{h}\right)$ de amostras de goiaba in natura e ao final das diversas etapas de processamento, conforme as diferentes soluções osmóticas utilizadas e secagem por convecção, sem desidratação por imersãoimpregnação ${ }^{(1)}$.

\begin{tabular}{|c|c|c|c|c|c|c|}
\hline Etapa $^{(2)}$ & $\begin{array}{c}\text { Sacarose } \\
0,5 \mathrm{~g} \mathrm{~mL}^{-1}\end{array}$ & $\begin{array}{c}\text { Sacarose } \\
0,4 \mathrm{~g} \mathrm{~mL}^{-1}\end{array}$ & $\begin{array}{l}\text { Sacarose } 0,3 \mathrm{~g} \mathrm{~mL}^{-1} \\
+ \text { sucralose } 0,2 \mathrm{~g} \mathrm{~L}^{-1}\end{array}$ & $\begin{array}{c}\text { Açúcar invertido } \\
41 \%(\mathrm{p} / \mathrm{p})\end{array}$ & $\begin{array}{c}\text { Açúcar invertido } \\
\text { sem diluição }\end{array}$ & $\begin{array}{c}\text { Secagem por convecção, } \\
\text { sem DII }\end{array}$ \\
\hline & & & & Parâmetro L* & & \\
\hline IN & $42,9 \mathrm{a}$ & $40,7 \mathrm{ab}$ & $41,3 \mathrm{a}$ & $44,7 \mathrm{a}$ & $41,9 \mathrm{a}$ & $42,8 \mathrm{a}$ \\
\hline IAA & $38,9 \mathrm{ab}$ & $37,8 b$ & $40,1 \mathrm{a}$ & $43,6 a$ & $40,9 a$ & $41,1 \mathrm{a}$ \\
\hline DII & $39,4 \mathrm{ab}$ & $38,7 \mathrm{ab}$ & $40,2 \mathrm{a}$ & $44,4 a$ & $46,4 a$ & $-^{(3)}$ \\
\hline $\mathrm{SC}$ & $42,7 \mathrm{a}$ & $43,8 \mathrm{a}$ & $42,9 a$ & $36,1 b$ & $34,5 b$ & $45,4 \mathrm{a}$ \\
\hline $30 \mathrm{D}$ & $35,5 b$ & $36,8 b$ & $40,1 \mathrm{a}$ & $32,8 b$ & $34,4 \mathrm{~b}$ & $45,2 \mathrm{a}$ \\
\hline $60 \mathrm{D}$ & $35,4 \mathrm{~b}$ & $37,2 \mathrm{~b}$ & $41,2 \mathrm{a}$ & $32,1 b$ & $34,7 b$ & $44,2 \mathrm{a}$ \\
\hline \multirow[t]{2}{*}{$90 \mathrm{D}$} & $35,3 b$ & $36,3 b$ & $41,4 \mathrm{a}$ & $31,9 \mathrm{~b}$ & $34,5 b$ & $45,2 \mathrm{a}$ \\
\hline & & & & Parâmetro a* & & \\
\hline IN & $25,7 b c$ & $22,9 \mathrm{bc}$ & $23,9 b$ & $24,4 \mathrm{~b}$ & $23,3 \mathrm{bcd}$ & $22,6 b$ \\
\hline IAA & $24,7 b c$ & $23,3 b c$ & $24,1 b$ & $24,0 \mathrm{bc}$ & $23,3 \mathrm{bcd}$ & $22,6 b$ \\
\hline DII & $27,1 b$ & $25,3 b$ & $25,2 b$ & $25,8 \mathrm{~b}$ & $26,6 \mathrm{ab}$ & - \\
\hline $\mathrm{SC}$ & $33,2 \mathrm{a}$ & $33,0 \mathrm{a}$ & $33,1 \mathrm{a}$ & $30,9 a$ & $30,1 \mathrm{a}$ & $30,5 a$ \\
\hline $30 \mathrm{D}$ & $25,1 \mathrm{bc}$ & $24,2 \mathrm{bc}$ & $26,5 b$ & $22,6 \mathrm{bc}$ & $24,3 \mathrm{bc}$ & $23,8 b$ \\
\hline $60 \mathrm{D}$ & $23,0 \mathrm{bc}$ & $21,7 \mathrm{bc}$ & $24,5 b$ & $20,1 \mathrm{~cd}$ & $22,3 \mathrm{~cd}$ & $21,9 b$ \\
\hline \multirow[t]{2}{*}{$90 \mathrm{D}$} & $21,7 \mathrm{~b}$ & $20,7 \mathrm{~b}$ & $23,4 b$ & $17,6 \mathrm{~d}$ & $19,8 \mathrm{~d}$ & $20,8 b$ \\
\hline & & & & Parâmetro b* & & \\
\hline IN & $14,2 \mathrm{ab}$ & $12,2 \mathrm{bcd}$ & $10,9 b$ & $14,0 \mathrm{a}$ & $14,3 \mathrm{ab}$ & $11,4 \mathrm{c}$ \\
\hline IAA & $11,8 \mathrm{~b}$ & $10,9 d$ & $10,5 b$ & $13,7 \mathrm{a}$ & $13,7 b$ & $11,0 \mathrm{c}$ \\
\hline DII & $12,7 \mathrm{~b}$ & $12,1 \mathrm{~cd}$ & $10,8 b$ & $14,0 \mathrm{a}$ & $16,5 \mathrm{ab}$ & - \\
\hline $\mathrm{SC}$ & $16,8 \mathrm{a}$ & $17,3 \mathrm{a}$ & $15,6 a$ & $13,7 \mathrm{a}$ & $17,1 \mathrm{a}$ & $17,9 b$ \\
\hline $30 \mathrm{D}$ & $13,5 b$ & $14,2 \mathrm{bc}$ & $15,8 \mathrm{a}$ & $12,9 a$ & $14,5 \mathrm{ab}$ & $20,6 \mathrm{ab}$ \\
\hline $60 \mathrm{D}$ & $13,8 b$ & $15,0 \mathrm{ab}$ & $16,9 a$ & $13,3 \mathrm{a}$ & $14,8 \mathrm{ab}$ & $20,8 \mathrm{a}$ \\
\hline \multirow[t]{2}{*}{$90 \mathrm{D}$} & $14,0 \mathrm{ab}$ & $14,5 \mathrm{abc}$ & $17,4 a$ & $12,8 \mathrm{a}$ & $14,8 \mathrm{ab}$ & $21,4 \mathrm{a}$ \\
\hline & & & & Ângulo ${ }^{\circ} \mathrm{h}$ & & \\
\hline IN & $34,2 b c$ & $34,9 \mathrm{~cd}$ & $30,7 \mathrm{c}$ & $38,5 \mathrm{bc}$ & $39,9 b$ & $32,8 \mathrm{c}$ \\
\hline IAA & $32,5 \mathrm{c}$ & $32,6 \mathrm{~d}$ & $29,1 \mathrm{c}$ & $37,3 b c$ & $39,0 \mathrm{~b}$ & $31,9 \mathrm{c}$ \\
\hline DII & $32,8 \mathrm{c}$ & $32,1 d$ & $28,9 \mathrm{c}$ & $36,6 \mathrm{bc}$ & $41,3 \mathrm{ab}$ & - \\
\hline $\mathrm{SC}$ & $37,0 \mathrm{abc}$ & $37,5 \mathrm{bcd}$ & $34,1 \mathrm{bc}$ & $34,6 \mathrm{c}$ & $38,9 \mathrm{~b}$ & $40,6 \mathrm{~b}$ \\
\hline $30 \mathrm{D}$ & $37,4 \mathrm{abc}$ & $39,9 \mathrm{abc}$ & $40,3 \mathrm{ab}$ & $39,9 \mathrm{abc}$ & $42,6 b$ & $52,6 a$ \\
\hline $60 \mathrm{D}$ & $40,5 \mathrm{ab}$ & $43,9 \mathrm{ab}$ & $44,5 \mathrm{a}$ & $42,3 \mathrm{ab}$ & $44,7 \mathrm{ab}$ & $55,0 \mathrm{a}$ \\
\hline $90 \mathrm{D}$ & $42,7 \mathrm{a}$ & $44,9 \mathrm{a}$ & $46,9 \mathrm{a}$ & $46,1 \mathrm{a}$ & $47,8 \mathrm{a}$ & $57,2 \mathrm{a}$ \\
\hline
\end{tabular}

${ }^{(1)}$ Valores seguidos por letras iguais, na coluna, não diferem entre si pelo teste de Tukey, a 5\% de probabilidade. ${ }^{(2)}$ IN: in natura; IAA: imersão em solução de ácido ascórbico; DII: desidratação por imersão-impregnação; SC: secagem por convecção; 30D, 60D e 90D: após 30, 60 e 90 dias de armazenamento a $7^{\circ} \mathrm{C}$. ${ }^{(3)} \mathrm{Não}$ houve etapa osmótica prévia. 
pelos provadores (Figura 1). Por sua vez, os participantes atribuíram nota 6 (gostei ligeiramente) e 7 (gostei moderadamente) para todas as características qualitativas avaliadas nas amostras de goiaba desidratada por imersão-impregnação. Levando-se em consideração o fato de que as frutas desidratadas, principalmente a goiaba, não fazem parte do hábito alimentar do brasileiro, todos os produtos desidratados por imersão-impregnação obtiveram boa aceitação. O incremento do sabor doce, evidenciado pelo aumento dos sólidos solúveis, a redução na acidez e a melhor estabilidade da cor, contribuíram para melhor aceitação dos produtos desidratados, em relação aos não desidratados, por imersão-impregnação.

As amostras desidratadas com adição do edulcorante sucralose foram tão bem aceitas quanto as demais, apesar de sua menor concentração de açúcar. Portanto, este tratamento pode ser promissor para utilização na desidratação de frutos voltados para o mercado "light". Resultado similar foi relatado por Mendonça et al. (2001), que verificaram que o uso de sucralose, em substituição parcial à sacarose, proporcionou à compota de pêssego "light" características sensoriais similares às de compotas convencionais, preparadas exclusivamente com sacarose.

Com relação aos resultados de intenção de compra de goiabas, desidratadas por imersão-impregnação e

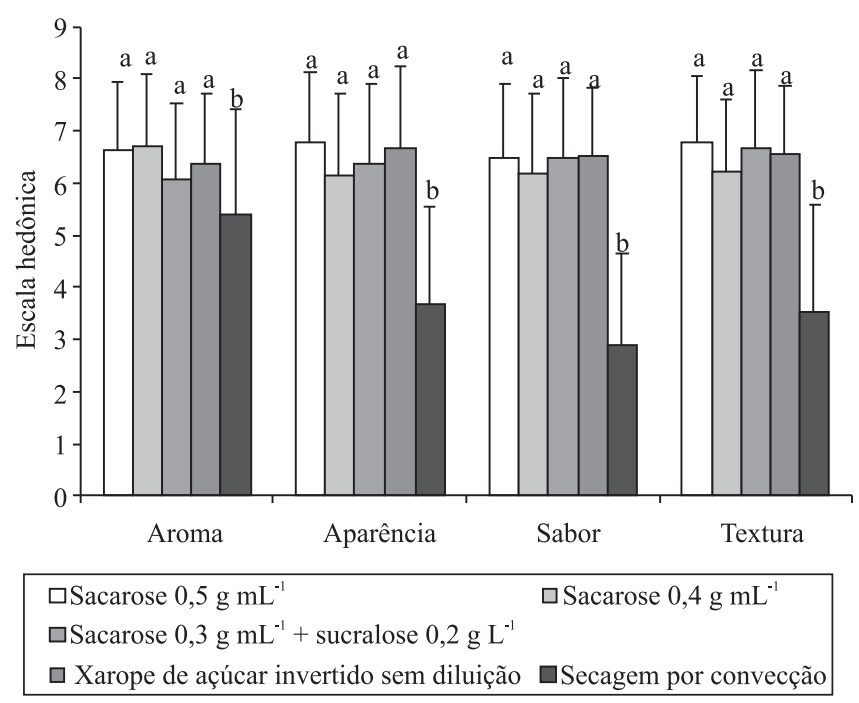

Figura 1. Avaliação sensorial de amostras de goiaba, desidratadas por imersão-impregnação nas diferentes soluções. Médias com letras iguais, para o mesmo atributo sensorial, não diferem entre si pelo teste de Tukey, a 5\% de probabilidade. secagem complementar por convecção, cerca de $60 \%$ dos participantes respondeu que compraria o produto.

Os resultados da análise sensorial corroboram as afirmações de Torreggiani \& Bertolo (2001) e Lenart \& Piotrowski (2001) sobre a melhoria da qualidade final de frutas secadas quando se emprega uma etapa de pré-tratamento osmótico antes da secagem final por convecção.

\section{Conclusões}

1. O teor de sólidos solúveis totais aumenta linearmente em função do tempo de desidratação.

2. A preservação do teor de ácido cítrico é maior em solução com menor concentração de sacarose.

3. Amostras não submetidas à desidratação por imersão-impregnação apresentam maior alteração de cor do que aquelas previamente desidratadas; soluções de sacarose são mais eficazes na estabilidade da cor do que as de açúcar invertido.

4. A secagem que inclui a desidratação por imersãoimpregnação resulta em produto sensorialmente mais aceito.

\section{Agradecimentos}

Ao $\mathrm{CNPq}$, à Faperj, à Finep e à International Foundation for Science (IFS), pelo apoio técnico e financeiro.

\section{Referências}

ALI, Z.M.; LAZAN, H. Guava. In: MITRA, S.K. (Ed.). Postharvest physiology and storage of tropical and subtropical fruits. New York: CAB International, 2001. p.145-165.

ASSOCIATION OF OFFICIAL ANALYTICAL CHEMISTS. Official methods of analysis of the Association of Official Analytical Chemists. $15^{\text {th }}$ ed. Arlington: AOAC, 1990. 1298p.

CALLIGARIS, F.; FALCONE, P.; ANESE, M. Color changes of tomato purees during storage at freezing temperatures. Journal of Food Science, v.67, p.2432-2435, 2002.

FORNI, E.; SORMANI, A.; SCALISE, S.; TORREGGIANI, D. The influence of sugar composition on the colour stability of osmodehydrofrozen intermediate moisture apricots. Food Research International, v.30, p.87-94, 1997.

GORINSTEIN, S.; ZEMSER, M.; HARUENKIT, R.; CHUTHAKORN, R.; GRAUER, F.; MARTIN-BELLOSO, O.; TRAKHTENBERG, S. Comparative content of total polyphenols and dietary fiber in tropical fruits and persimmon. Journal of Nutritional Biochemistry, v.10, p.367-371, 1999.

IKOKO, J.; KURI, V. Osmotic pre-treatment effect on fat intake reduction and eating quality of deep-fried plantain. Food Chemistry, v.102, p.523-531, 2007. 
KROKIDA, M.K.; KIRANOUDIS, C.T.; MAROULIS, Z.B.; MARINOS-KOURIS, D. Drying related properties of apple. Drying Technology, v.18, p.1251-1267, 2000.

LAZARIDES, H.N.; GEKAS, V.; MAVROUDIS, N. Apparent mass diffusivities in fruit and vegetable tissues undergoing osmotic processing. Journal of Food Engineering, v.31, p.315-324, 1997.

LENART, A. Osmo-convective drying of fruits and vegetables: technology and application. Drying Technology, v.14, p.391-413, 1996.

LENART, A.; PIOTROWSKI, D. Drying characteristics of osmotically dehydrated fruits coated with semipermeable edible films. Drying Technology, v.19, p.849-877, 2001.

MAESTRELLI, A.; LO SCALZO, R.; LUPI, D.; BERTOLO, G.; TORREGGIANI, D. Partial removal of water before freezing: cultivar and pre-treatments as quality factors of frozen muskmelon (Cucumis melo, cv. reticulatus Naud.). Journal of Food Engineering, v.49, p.255-260, 2001.

MENDONÇA, C.R.; ZAMBIAZI, R.C.; GULARTE, M.A. Caracterização de compotas de pêssego elaboradas com a substituição parcial de açúcar por sucralose e acesulfame-K. Brazilian Journal of Food Technology, v.4, p.95-101, 2001.

PANADÉS, G.; FITO, P.; AGUIAR, Y.; VILLAVICENCIO, M.N. de; ACOSTA, V. Osmotic dehydration of guava: influence of operating parameters on process kinetics. Journal of Food Engineering, v.72, p.383-389, 2006.

PARK, K.J.; BIN, A.; BROD, F.P.R. Drying of pear 'd'Anjou' with and without osmotic dehydration. Journal of Food Engineering, v.56, p.97-103, 2002.

PEIRÓ, R.; DIAS, V.M.C.; CAMACHO, M.M.; MARTÍNEZNAVARRETE, N. Micronutrient flow to the osmotic solution during grapefruit osmotic dehydration. Journal of Food Engineering, v.74, p.299-307, 2006.

QUEIROZ, V.A.V.; FERREIRA, K.S.; MONNERAT, P.H.; QUEIROZ, L.R.; DOLINSKI, C. Na, K, Ca, Mg, Fe, Zn, $\mathrm{Cu}$ and $\mathrm{Se}$ contents in fruits consumed in Brazil. Nutrire, v.31, p.61-73, 2006.

RAOULT-WACK, A.L.; LENART, A.; GUILBERT, S. Recent advances in the osmotic dehydration of foods. Trends in Food Science \& Technology, v.5, p.255-260, 1994.

RIBEIRO JÚNIOR, J.I. Análises estatísticas no SAEG. Viçosa: UFV, 2001, 300p.

RIVA, M.; CAMPOLONGO, S.; LEVA, A.A.; MAESTRELLI, A.; TORREGGIANI, D. Structure-property relationships in osmo-airdehydrated apricot cubes. Food Research International, v.38, p.533-542, 2005.

SOUSA, P.H.M.; MAIA, G.A.; SOUZA FILHO, M.S.M.; FIGUEIREDO, R.W.; SOUZA, A.C.R. Goiabas desidratadas osmoticamente seguidas de secagem em estufa. Revista Brasileira de Fruticultura, v.25, p.414-416, 2003.

TORREGGIANI, D.; BERTOLO, G. Osmotic pre-treatments in fruit processing: chemical, physical and structural effects. Journal of Food Engineering, v.49, p.247-253, 2001.

VALERA, A.; ZAMBRANO, J.; MATERANO, W.; QUINTERO, I. Efectos de la concentración de soluto y la relación fruta/jarabe sobre la deshidratación osmótica de mango en cilindros. Agronomía Tropical, v.55, p.117-132, 2005.

WILBERG, V.C.; RODRIGUEZ-AMAYA, D.B. HPLC quantitation of major carotenoids of fresh and processed guava, mango and papaya. Lebensmittel-Wissenschaft und-Technologie, v.28, p.474-480, 1995.

Recebido em 3 de maio de 2007 e aprovado em 24 de agosto de 2007 